\title{
Transport Costs and "Natural" Integration in Mercosur
}

\author{
Azita Amjadi \\ The World Bank \\ L. Alan Winters \\ University of Sussex \\ London School of E conomics
}

\begin{abstract}
The paper explores the argument that trade between the M ercosur countries should be stimulated by preferential policies because of their geographic proximi ty. That is, that the M ercosur countries are candidates for "natural" integration. The paper finds that, on average, transportation margins on trade within M erco sur and between Mercosur and Chile are about 6 percentage points lower than on trade with the rest of the world. That is a significant margin, and one that was reflected in the countries' trade patterns even before regional trade agree ments reduced the policy-based barriers to mutual trade. But it is probably not large enough, in and of itself ( without other benefits), to make the introduction of trade preferences desirable. The paper also explores the argument that absolutely high transportation costs between M ercosur and the rest of the world (that is, not

* Correspondence Address: School of Social Sciences, University of Sussex, Falmer, Brighton, BN1 9SN, UK; (E-mail) I.a.winters@sussex.ac.uk; We are grateful to participants in the World Bank's "M ercosur Seminar" and M aurice Schiff for comments on earlier drafts and to Audrey Kitson-Walters, Sarah Lipscomb, and M inerva Patena for logistical support. Naturally they are not responsible for the paper's remaining defects. This paper represents only the views of the authors and should in no way be attributed to the World Bank.
\end{abstract}

(C1999 - Institute for International Economics, Sejong Institution. All rights reserved. 
relative to intra-M ercosur costs) justify regional trade preferences. For this to apply the introduction of trade preferences must cause the M ercosur countries to cease importing some goods from the rest of the world completely. While M er cosur---rest-of-the-world transport costs certainly are high, trade patterns sug gest that very few goods will cease to be imported from the rest of the world. (JEL-Classifications: F15, R40) 《ey Words: economic integration, transport costs, regional trade preferences.>

\section{Introduction}

One theme of the recent debate about the virtues of regional trading arrangements has been the notion of "natural" trading partners. Defined in terms of the existing level of trade between the prospective partners this is not a particularly useful concept, for trade is plainly endogenous with respect to the policy environment. If we define "natural" in terms of unavoidable transactions costs, on the other hand, there does appear to be content in the idea. Transportation costs have a strong exogenous component and so could be useful in this regard, as Frankel, Stein and Wei [1995] have demonstrated. They define a bloc as natural if moving to free trade within it raises the welfare of its members. Strictly speaking, this definition is also circular, but the basis of the welfare effect Frankel et al derive is lower transportation costs within the bloc than between it and the outside world, and so it is basically operational. In transportation terms the creation of M ercosur would seem to be a prime candidate for the soubriquet "natural": the member countries are contiguous but isolated from the rest of the world. Hufbauer and Schott [1994] have, for example, suggested that M ercosur is a natural trading bloc.

The paper seeks to explore this characterization of M ercosur directly by offering empirical evidence on the costs of transportation on international trade within $M$ ercosur and between the Mercosur countries and their principal trading partners. There are many transactions costs on international trade that we cannot capture. On the basis of the evidence we do have, however, it appears that while exploiting differences in transportation costs may generate some benefits from M ercosur's moving to internal free trade, these will be small. The justification for creating the bloc must be sought elsewhere. For 
the purpose of comparison, and because of the recent moves towards closer integration, we also include Chile in our empirical work. Thus the set of countries whose transportation costs we examine and which we loosely refer to as "M ercosur" is Argentina, Brazil, Paraguay, Uruguay and Chile.

Section II of this paper considers the role of transportation costs in the theory of regionalism in the context of models of differentiated products. This model, developed by Frankel, Stein and Wei [1995], focuses on the difference between intra- and inter-bloc transportation costs and argues that the larger it is the more beneficial is integration. The model has two particular features which appear to reduce its applicability to the real world, however - see section II.A: (a) despite having a production sector, it is effectively an endowment model, and (b) all costs of transportation are borne by consumers. Section II.B discusses a source of detailed transportation costs data and section II.C presents results on the differences between Mercosur's intra and inter-bloc costs. These average about 6 to 8 percentage points (6\%to $8 \%$ of the non-transport cost of the transaction). F rankel et al's model is not readily related to the real world, but their results suggest that, by itself, a $6 \%$ differential is not enough to generate significant gains from intra-bloc free trade.

Section III of the paper shifts to a more traditional model with homogeneous goods, in which it is only transportation costs with the rest of the world that matter. This model also has particular features underlying its conclusion that transportation costs can allow scope for additional benefits from integration: specifically, if two members of the bloc trade a good after integration, the exporter should have had no other market before integration and the importer no other supplier after integration. Although M ercosur's costs of trading with the rest of the world are high enough to promise scope for significant gains from regional preferences, few commodities meet even the second of these conditions.

Section IV of the paper extends the exercise to ask whether it is realistic for $M$ ercosur countries to aim to reduce their transportation costs with the rest of the world. For a series of distant suppliers we compare the transport component of import costs for M ercosur with that for imports to the United States. In general the evidence suggests that Mercosur buyers pay a few percent more than American buyers and that therefore there is some scope for efficiency gains. In fact, since 1993-the year of our data-a number of 
reforms and modernizations have occurred, so the M ercosur countries may already be reaping these gains. Finally, section $\mathrm{V}$ concludes.

\section{Transport Costs in Models of Differentiated Products}

\section{A. Theory}

One approach to the role of transport costs in the theory of regionalism stems from J eff Frankel's extension of Paul Krugman's two celebrated contributions [1991a, b]. Frankel, Stein and Wei [1995] envision a symmetric world of $\mathrm{C}$ continents each of $\mathrm{N}$ countries. Transport costs are of the iceberg type such that intra-continental trade entails a wastage factor of a -that is, of each unit shipped, only (1-a) arrives - and inter-continental trade an additional wastage of b-only (1-a) (1-b) arrives. Within each country, goods are produced by labor alone, with a fixed cost and constant marginal cost, $I=\alpha+\beta x$ where $I$ is labor demand and $x$ output. (Symmetry means that all goods are identical so we need no subscripts here). Consumers around the world maximize a utility function, $u=\sum c_{i}$, subject to a budget constraint, where i counts across goods and $(1-\theta)^{-1}$ is the elasticity of substitution between goods. All goods are consumed in positive quantities. Imported goods face a tariff $t$, which is not levied on partners in an integration scheme.

While this model is elegant and powerful, it does have some very particular features. First a series of now standard manipulations shows that the number of products produced in each economy $(n)$ is constant $[n=L(1-\theta) / \alpha]$, output of each good is constant $[x=\alpha \theta / \beta(1-\theta)]$, and producer prices are constant $[p=\beta w / \theta]$, where $w$ is the wage, which is also constant because of the constant marginal input-output coefficient. Thus this is effectively an endowment model.

Now consider the form of transportation costs. Iceberg costs have the analytically attractive feature that they do not affect the elasticity of demand. It is this that permits the invariance on the production side that we have just noted. The fixed producer price means that consumers bear all the cost of transportation; their welfare is affected only through the prices they face. Consumers choose between three types of goods:

- domestic goods, presumed to be free of all trade costs, at price p;

- "partner goods" from other countries on the continent at price 
$p_{p}=p /(1-a)+p t$

- where $t$ is the tariff, which will be removed if the continent integrates; ${ }^{1}$

and

- "non-partner goods" from other continents at price

$p_{n}=p /(1-a)(1-b)+p t$.

Integration changes the proportions in which consumers buy these goods by removing a distortion between domestic and partner goods, and introducing one between partner and non-partner goods. As in traditional customs union theor $y$, such changes might or might not have beneficial effects as consumer surplus is traded against lost tariff revenue. In this model, however, they also have a second effect, by changing the net wastage of goods on transportation: they switch some demand from goods with zero transport costs to those with costs $a$, which absorbs resources, and some from goods with costs $(a+b-a b)$ to those with $a$, which releases resources. Again the net effect is ambiguous. The balance of these effects depends on the vector of parameters in a complex fashion and Frankel, Stein and Wei are able to solve their model only numerically. They find, however, that the increase in the welfare stemming from intra-continental free trade (which is assumed to proceed symmetrically on all continents) is larger the higher is b, the inter-continental transport factor. Essentially, a higher wastage factor reduces consumption of non-partner goods; this reduces absolutely the degree of trade diversion and although the distortion cost of a unit of diversion is higher because the marginal value of the "under-consumed" goods is higher, this latter effect is off-set by the fact that any diversion that does occur offers a large real resource saving in terms of transportation.

It is very difficult to know how to relate models such as this to reality, but F rankel, Stein and Wei pay a lot of attention to the results of one particular simulation, with three continents each of two countries, an elasticity of substitution of four, tariffs of $30 \%$ and zero intra-continental transportation costs $(a=0)$. This constellation of values suggests that if inter-continental costs, $b$, fall below about 15 percentage points (and hence exceed intra-continental costs

1. It is not particularly significant to the results that the tariff is levied on the producer price. In this model, where transport costs subtract value, this formulation is equivalent to paying the tariff on the c.i.f. price. 
by that amount), then integration reduces welfares - it is, in their term, "super-natural." Frankel, Stein and Wei are frank that some sets of parameters - e.g. less substitutability coupled with higher tariffs - do not generate losses for any value of $b$, and $N$ itsche [1996] suggests the same conclusion if intra-continent transport costs, $a$, were increased from zero to 0.05 in the basic model. Thus while one clearly can not take these results too seriously, they do seem to suggest that unless inter-continental transport costs are quite high, there is not much mileage in the notion that transportation cost differences offer a case for regional integration along "natural bloc" lines.

The critical empirical magnitude in the discussion above is the relative size of intra and inter-continental transport costs. The rest of this section is devoted to measuring this for M ercosur, first describing the available data and then examining some results.

\section{B. Data on Transportation Costs}

Data on M ercosur imports were obtained from the ALADI Secretariat to whom we are most grateful. They are available for the years 1991 through 1994 with the exception of Uruguay which lacks [1991,2] and Argentina [1991]. We restrict our analysis to 1993, however, because we have similar data on US imports and transport costs for this one years - - -see Amjadi, Winters and Yeats [1996]. The data are recorded at the 6-digit level of the Harmonized System (HS), and they record import values (f.o.b.) in US\$, transport and insurance costs, and quantities. Since we have import charges only as a total for the United States, we add the M ercosur transport and insurance components to calculate what we call the transport costs in this paper.

The U nited States tabulates imports, by product and country, on a joint free-alongside-ship (f.a.s.) and cost-insurance-freight (c.i.f.) basis. According to the US practice, the f.a.s. valuation includes the purchase price of the product plus all charges incur red in placing merchandise along side the vessel at the port of exportation. The difference between the c.i.f. and f.a.s. valuations reflect loading costs plus transport and insurance costs for the international segment of the journey excluding the costs of unloading. ${ }^{2}$

2. In this regard M ercosur data differ from US data which include unloading. 
For both groups, transportation costs are expressed as a proportion of the value of trade in the heading. The tables below report statistics- - -including various weighted averages of these individual heading data.

\section{Relative Transportation Costs on Mercosur's I mports}

The theories built around differentiated goods and imperfect competition stress the differences between intra- and inter-bloc transportation costs as determinants of the benefits of regional integration. Table 1 addresses these concerns directly, comparing transportation costs of trade within M ercosur with those applying to the bloc's imports from elsewhere. It is clear from the first two rows that average transportation costs on intra-M ercosur trade are lower than those on trade with the rest of the worlds -- -but, at about 6 percentage points for the two main countries, not massively so.

In fact the results in table 1 probably slightly exaggerate the difference in transport costs between Mercosur and non-M ercosur suppliers because

Table 1

Average Transportation Costs on Imports to Mercosur Countries and Chile, 1993 ${ }^{\mathrm{a}}$

\begin{tabular}{l|c|c|c|c|c|}
\hline \multicolumn{7}{|c|}{ M arket } \\
\hline Exporter & Argentina & Brazil & Paraguay & Uruguay & Chile \\
\hline Mercosur & 6.2 & 5.6 & 10.8 & 2.6 & 8.9 \\
Rest of World & 12.3 & 12.2 & 22.7 & 14.0 & 12.7 \\
$\quad$ (except Chile) & & & & & \\
Argentina & - & 6.0 & 12.2 & 2.4 & 8.3 \\
Brazil & 6.7 & - & 10.4 & 3.3 & 9.2 \\
Paraguay & 6.3 & 2.6 & - & 4.9 & 10.9 \\
Uruguay & 4.6 & 6.2 & 16.2 & - & 16.1 \\
Chile & 8.1 & 10.7 & 14.5 & 8.0 & - \\
Europe & 11.3 & 12.4 & 18.8 & 12.5 & 13.2 \\
US-Canada & 14.5 & 15.4 & 23.8 & 12.1 & 12.5 \\
Asia & 16.8 & 19.3 & 25.5 & 16.2 & 14.9 \\
\hline
\end{tabular}

a) Weighted averages using imports from M ercosur as weights. Trade flows with reported costs of zero excluded. 
they are calculated using weights from the former. For fairly obvious reasons average costs seem lower when one uses a country's own exports as weights. The figures also exclude flows with recorded transportation costs of zero. The bias that this causes is unclear. To the extent that such flows represent shipments crossing at a land frontier (e.g., Argentina-U ruguay), omitting this leads us to understate the advantages of intra-M ercosur trade. However, this is off-set by a counteracting force. Our criterion entails observing zero transport costs on all shipments of a particular heading in a year. If $(\mathrm{N}-1)$ of them record zero, but the $\mathrm{N}$ th records positive costs, our annual data show very low average transport costs for the year. In one sense this is a reasonable average, but if the heading is heterogeneous such that, say, varieties that the rest of the world can supply must travel by air while those that only M ercosur can supply travel by road, the average for M ercosur over the two sorts of good will overstate Mercosur's transport advantage on the "outside" good.

In fact, however, many of the zero-cost flows look to arise from conceptual problems or recording errors: Uruguay records more such flows with nonM ercosur partners (6\%of imports), than M ercosur partners (4\%), and B razil reports some (4\%) on imports from North America. These may reflect transshipment consignments which should for our purposes be associated with the costs of their first leg. Overall, therefore, there is little that can be made out of the zeros.

We also considered two further refinements of table 1. Although for each entry in the table the transport costs for each heading are weighted together by the same weights (M ercosur's imports of the heading from M ercosur), there are still cases in which a particular heading has to be omitted from a particular importer-exporter average because it has no recorded trade for that pair. Thus we have also recalculated the averages for Argentina, Brazil and Chile using precisely the same set of headings along each row (i.e., we have included only headings for which all three importers have imports from M ercosur and non-M ercosur respectively). It makes no material difference. Second we have recalculated the top two rows of the table using precisely the same set of headings for each entry in a given columns - that is, comparing transport costs only on goods that the importer concerned imports from both Mercosur and from the rest of the world. This widens the margin 
between Mercosur and the rest of the world trade by 0.7 percentage points for Argentina, 1.7 for Brazil, 2.3 for Paraguay, 7.7 for Uruguay and 0.2 for Chile. Except for Uruguay--for which no data seem wholly reliable--these do not change the basic argument that the difference between the two sets of transport costs is not a major factor in the case for integration.

\section{Homogeneous Goods}

\section{A. A Model}

We turn now to an alternative model which deals only with homogeneous goods. The role of transportation costs in integration theory was first isolated by Wonnacott and Wonnacott [1981] ---hereafter WW81. They argued that- - -contrary to the prevailing wisdoms - --integration between neighboring countries could offer benefits that were not available to either partner individually through unilateral trade liberalization.

In essence, they argued, preferences between neighbors could divert trade with the rest of the world, which was expensive in terms of transportation costs, to take place instead with neighbors which were cheaper partners in transportation terms. The resulting savings of real resources would allow one partner to experience a terms of trade of gains - - either the exporting partner saving the costs of shipping the good to the rest of the world or the importing partners saving the cost of shipping in from there.

The original WW 81 argument is illustrated in figure 3.1. Country C, the rest of the world, is large and hence has straight-line offer curves vis-a-vis the two potential partners, A and B. Trade with either A or B, however, entails transport costs and so the relative price at which $C$ will sell $X$ for $Y$ differs from that at which it will sell $Y$ for $X$. Specifically, if $A$ or $B$ sells $X$ it faces offer curve $O_{c}^{X}$, while if it sells $Y$ it faces $O_{C}^{Y}$. ( $C$ 's internal terms of trade lie in-between.) Now introduce $A$ 's and B's offer-curves, each distorted by an mfn tariff but assume that trading between themselves involves no transactions costs. (This means that the same offer curve describes an $A$ / $B$ trade from both partners' points of view.) Thus $A$ exports $X$ along $O_{A}^{1}$ and $B$ exports $Y$ along $\mathrm{O}_{\mathrm{B}}^{1}$.

Imagine first that there were no transport costs and that $C$ were prepared 


\section{Figure 3.1}

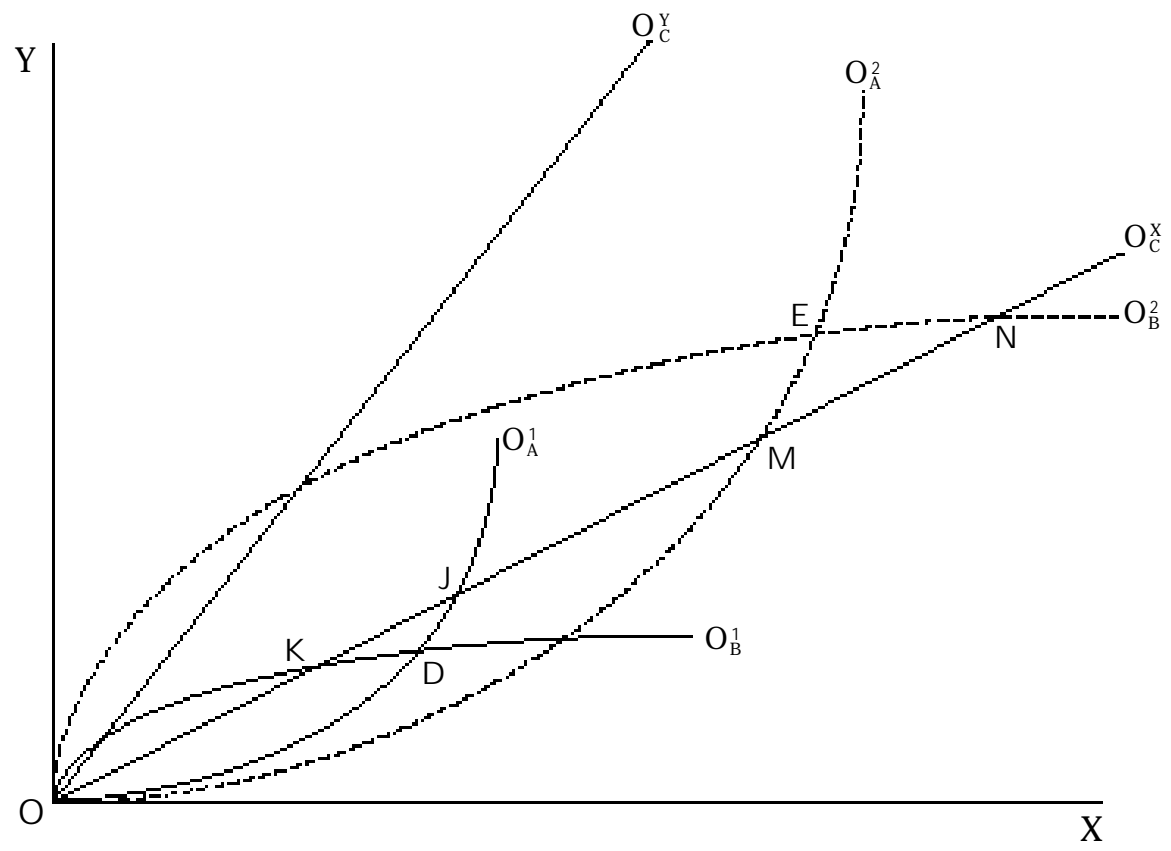

to buy or sell $X$ at any point along $O_{C}^{X}$. With ( $m f n$ ) tariff-ridden offer curves $O_{A}^{1}$ and $O_{B}^{1}$ and no trade with $C, A$ and $B$ could trade with each other to point $D$. But $A$ can do better than this by selling $X$ to $C$ to attain point $J$, and $B$ will be left out of international commerce unless it too offers prices competitive with $O_{c}^{X}$. This it will do (rather than have no trade) and buy $X$ to achieve point $\mathrm{K}$. (With no transport costs with either $A$ or $C$ it is indifferent about which partner it trades with, but when we introduce such costs it will be evident that $A$ and $B$ will trade to point $K$ and $A$ and $C$ will then trade further to take $A$ to point J.)

Now suppose that $A$ and $B$ form a $C U$ offering each other tariff-free access along $O_{A}^{2}$ and $O_{B}^{2}$. Technically they could trade at point $E$. This is desirable for $A$, whose terms of trade improve from $J$ to $E$; $A$ also prefers it to unilateral liberalization which would take it only to point $M$. For $B$, on the other hand, the $\mathrm{CU}$ may or may not dominate the initial point $\mathrm{K}$-there is more trade but on less favorable terms; $E$ is clearly dominated, however, by point $\mathrm{N}$ which $\mathrm{B}$ could achieve by unilateral mfn liberalization. (Recall that we have temporarily assumed that $C$ will buy or sell $X$ along $O_{C^{\prime}}^{X}$ ) In other 
words, the CU does not make sense for B. M oreover, as WW assert, A cannot simultaneously compensate $B$ to move from $N$ to $E$ and gain itself relative to $M$. In summary, when there are no transport costs with $C$, creating a $\mathrm{CU}$ between $\mathrm{A}$ and $\mathrm{B}$ is dominated by unilateral liberalization for one party and hence does not offer a viable alternative.

Now modify figure 3.1 to recognize transport costs with $C$. To make use of the same diagram, assume that $C$ will continue to buy $X$ along $O_{c}^{X}$ but sell $X$ (buy $Y$ ) only along $O_{C}^{Y}$. The initial equilibrium is at $K$ and $J$ as before, with $C$ 's relative price for buying $X$ defining the terms of trade between $A$ and $B$. $B$ buys its $X$ from $A$ at the same price as $C$ does, which is considerably better than it could do by buying from $C$ along $O_{C}^{Y}$. A buys its $Y$ partly from $B$ (up to $\mathrm{K}$ ) and partly from $\mathrm{C}(\mathrm{KJ}$ ).

When $A$ and $B$ form a $C U$ the equilibrium $E$ arises again, but now it is potentially desirable from both $A$ 's and $B$ 's viewpoints. The story for $A$ is as before, while that for $B$ contrasts $E$ not with $N$ but with $M$, its best alternative with (partial) unilateral liberalization. With $A$ on offer curve $O_{A}^{2}, B$ benefits by gradually liberalizing, gradually pushing its offer curve out toward $\mathrm{O}_{\mathrm{B}}^{2}$. The equilibrium moves out along $\mathrm{O}_{\mathrm{C}}^{\mathrm{x}}$ until at $\mathrm{M}, \mathrm{B}$ just takes all $\mathrm{A}^{\prime} \mathrm{s}$ exports, but at prices defined by $C$ (because $C$ still provides the marginal potential trade). As B liberalizes further it moves towards $E$ which may or may not be better than $M$. The apparently desirable option of expanding further along $\mathrm{O}_{\mathrm{C}}^{\mathrm{X}}$ to $\mathrm{N}$ is not available, because purchasing $\mathrm{X}$ beyond what $\mathrm{A}$ will sell at point $M$ requires either paying more to $A$ 's producers (along $M E$ )

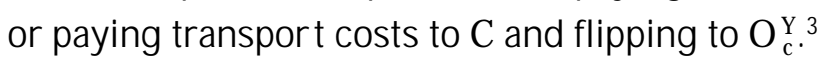

Figure 3.2 summarizes the above argument in what to many people appears to be a more accessible, partial equilibrium, fashion. This is also useful in illustrating the empirical applications which we undertake below. We imagine the market for an import in country A. For simplicity, we assume that there is no domestic production, but, fundamentally, we assume that prior to integration $A$ buys from both $B$ and $C .{ }^{4}$ Country $C$ is

3. This analysis looks at B's options after A has liberalized. Strictly speaking, unilateral liberalization would entail expanding from $\mathrm{K}$ to $\mathrm{J}$ and then along $\mathrm{O}_{\mathrm{A}}^{1}$, which is less attractive than the case in the text.

4. Wonnacott and Wonnacott [1992]-WW92-offer similar diagrammatic expositions of the simpler case in which $A$ imports only from $B$ both before and after integration. 


\section{Figure 3.2}

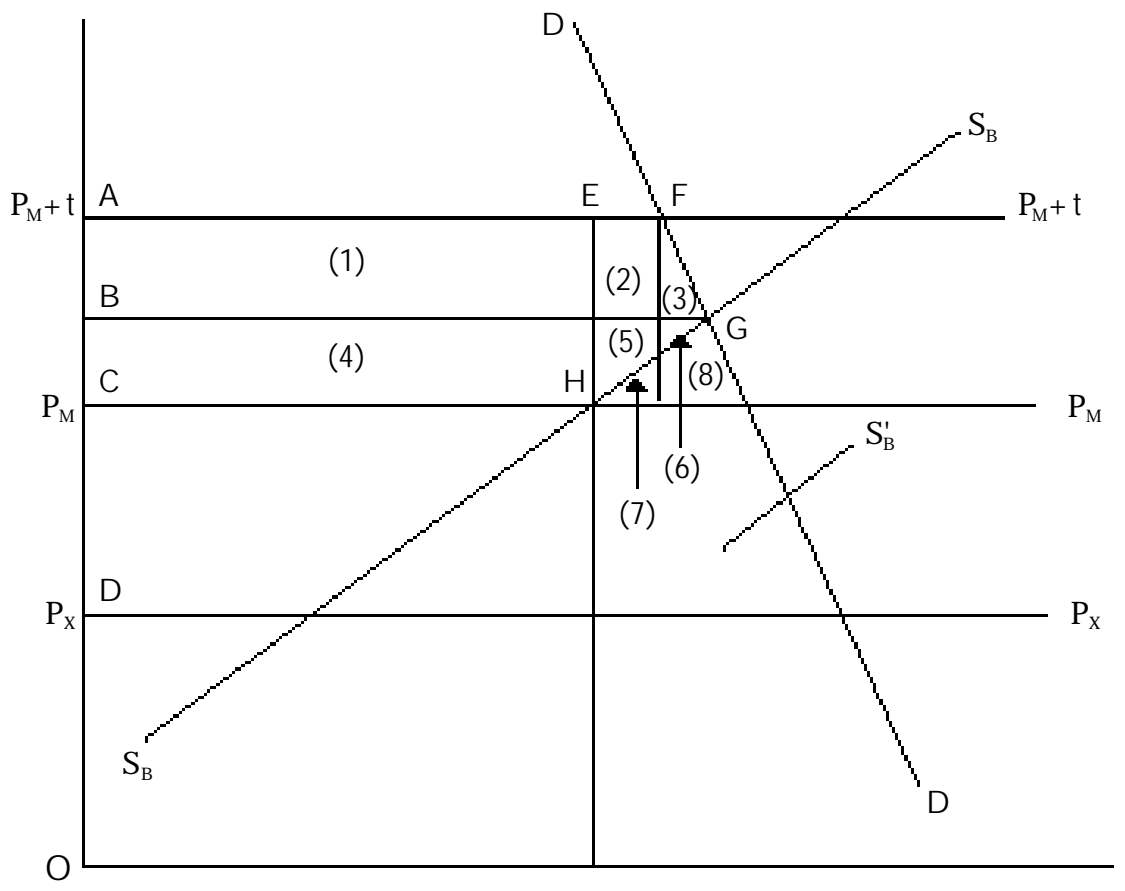

prepared to buy the good from $A$ or $B$ at a price that yields the suppliers returns of $P_{X}$, and to sell it to $A$ at price $P_{M}$ where $\gamma=\left(P_{M}-P_{X}\right)$ is the wedge due to transportation cost and tariffs in $\mathrm{C}$. In addition $A$ imposes an mfn tariff of $t$, making its pre-integration internal price $\left(P_{M}+t\right)$. Country $B$ supplies $\mathrm{CH}(=\mathrm{AE})$, the quantity on its supply curve, $S_{B}$, at $A$ 's border price, and countr $y C$ supplies $E F$, the remaining demand at $A$ 's internal price.

Now let $A$ offer $B$ tariff-free access to its market. The latter now receives $A$ 's internal price and expands supply along $S_{B}$. At the new equilibrium, $G$, $B$ becomes the sole supplier and A's internal price falls below the tariffinclusive price of C's supplies. Consumers in A gain areas $(1)+(2)+(3)$, producers in B gain $(4)+(5)+(6)$ and government in A loses $(1)+(2)+(4)$ $+(5)+(7)$. This is a trade diverting union and it could clearly be welfare reducing overall [if (3) $+(6)<(7)$ ], but, if it is not, it could provide the basis for benefits not available to either A or B unilaterally. Imagine that B has a market exactly symmetric to that in figure 3.2. If $A$ and $B$ swap mutual access concessions, each gains ( 3$)+(6)-(7)$. Of course, both of $A$ and $B$ 
could do better through concerted mfn liberalizations - - -each gaining (3) + (6) + (8). WW92 argue that this would not be unilateral liberalization correctly interpreted because it requires two countries to act, but on the other hand, if $A$ and $B$ can agree to form a customs union could they not also agree to concerted $\mathrm{mfn}$ liberalization ${ }^{5}$

Figure 3.2 does not replicate the result in figure 3.1 because the latter shows B's supply curve of A's importable shifting outwards as a result of integration - essentially because integration reduces distortions in $B$. In figure 3.2 this would result in a supply curve such as $S_{B}^{\prime}$, which would entail larger gains than previously. Indeed, it is only with such efficiency gains that the new equilibrium could have a price between $P_{X}$ and $P_{M}$. N ote also that under this assumption a concerted mfn liberalization would result in exactly the same outcome as the customs union.

Several points should be noted about these examples in which the existence of transport costs adds to the case for regional integrations - that is, on the issue of transportation costs and natural trading blocs. First, contrary to the statements in WW, there is no role in any of this for transport costs between the partners. It makes essentially no difference whether $S_{B}$ in figure 3.2 or $O_{B}$ in figure 3.1 reflects efficient production and very high intrabloc transportation or inefficient production and zero transportation costs. All that matters is the delivered price of B's exports to A.

Second, the gains from integration rely on members of the bloc ceasing to trade with the rest of the world. If, after integration, trade continued with the (large) rest of the world, A's internal prices would not change, there would be no consumer gains and consequently joining a customs union would merely give away tariff revenue, see, for example, Bhagwati and Panagariya [1996] or Schiff [1996].

Third, prior to integration, the exporting partner exported only to the other regional partner. In Figure 3.1 countr y $B$, which sells good $Y$ in return for $X$, can choose to sell to $C$ at price $O_{c}^{Y}$ or to $A$ at price $O_{c}^{X}$, the (better) price at which $C$ is prepared to sell $Y$ to country $A$. It clearly prefers the latter.

5. The answer could clearly be "no" once we add producer lobbies into the determination of policy-see, e.g., Winters [1996]. 


\section{B. The Transport Wedge}

A critical factor in the homogenous good model's prediction of beneficial regional integration is the wedge between the bloc's buying and selling prices on world markets--- the size of the pencil between $\mathrm{O}_{c}^{X}$ and $\mathrm{O}_{c}^{Y}$ in figure 3.1. This depends on transport costs on both exports and imports. No country can effectively collect data on the transportation costs levied on its exports and so we are obliged to represent the world by the United States, the only other country for which data on the transport component on imports is available. Fortunately this is not too large a distortion for the Mercosur countries, although, of course, it would be highly desirable to extend the analysis to their other major markets such as the EU and J apan.

Treating the United States as a large market and supplier, and representing its domestic price by $P_{D}, M$ ercosur suppliers could receive $P_{D}-\gamma_{U M}$ by selling in the United States, where $\gamma_{U M}$ is the cost of transportation from M ercosur to the United States, while M ercosur purchasers would need to pay $P_{D}+\gamma_{U M}$ to obtain supplies from the U nited States, where $\gamma_{U M}$ is the cost of transportation from the United States to M ercosur. These define $P_{x}$ and $P_{M}$ respectively in figure 3.2. The overall transportation wedge is $\left(\gamma_{M U}+\gamma_{U M}\right)$ which determines the range inside which $M$ ercosur domestic factors could influence the M ercosur price.

The range will actually be larger than this to the extent that Mercosur and the US levy tariffs on their mutual trade, but it will be smaller to the extent that US mark-ups are larger than the sum of the costs of internal transportation on M ercosur exports and imports in the United States. ${ }^{6}$ Thus by way of compromise here we look merely at the transportation wedge. T wo fur ther complications condition the interpretation of our results. First, in order to measure the transportation costs on flows in both directions between the United States and Mercosur, we need to observe

6. Let US producers receive $P_{1}$ and US consumers pay $P_{2}$, implying a mark-up of $m: P_{2}$ $=P_{1}+m$. M ercosur exporters will receive $P_{X}=P_{2}-\gamma_{M U}-t_{U S A}-r_{U S A}$ where $t_{U S A}$ is the tariff and $r_{U S A}$ is the US internal transportation cost on M ercosur exports. M ercosur consumers will pay $P_{M}^{\prime}=P_{1}+\gamma_{U M}+t_{M E R}+S_{U S A}$ where $t_{M E R}$ is $M$ ercosur's tariff and $S_{U S A}$ is the US transport component on US exports. The M ercosur "transaction wedge" is $P_{M}^{\prime}-P_{X}=\left(\gamma_{M U}+\gamma_{U M}\right)+\left(t_{U S A}+t_{M E R}\right)+\left(r_{U S A}+S_{U S A}\right)-m$. 
flows in both directions -i.e., we need two-way trade. This is consistent with there being homogeneous goods if one member of M ercosur exports the good and another imports it, but we have not insisted on this condition in this initial investigation.

The second complication concerns how to combine transportation costs in the two directions. We normally express unit transportation costs as a percentage of the unit value of the goods. If the latter varies significantly in the two directions, however, summing the two percentages is rather uncomfortable, because the denominators are not strictly comparable. Where the United States and Mercosur report trades in the same physical units we could calculate transport costs per unit. But this still leaves the problems of expressing the summed costs relative to something in order to make them comparable across commodities and of deciding which price to use as the anchor of the range. We have, therefore, decided merely to sum the percentage costs. Given that M ercosur imports generally have higher unit values and higher percentage transport costs than M ercosur exports, this will arguably understate the actual wedge. ${ }^{7}$

O ur transport wedges based on two-way M ercosur-US trade are calculated at the 6-digit level of the HS, the US data being aggregated to that level- - see Amjadi, Winters and Yeats [1996] for details of the US data. They refer only to categories for which at least $\$ 30,000$ of trade was observed in each direction in 1993; ruling out very small flows helps to eliminate very noisy transportation estimates. In all 641 headings met our criteria for inclusion; on average they have transportation wedges of $24 \%$ (mean) or $20 \%$ (median); roughly one quarter of them are below $15 \%\left(Q_{1}=15.2 \%\right)$ and another quarter above $29 \%\left(Q_{3}=29.1\right)$. These figures suggest considerable margins in which intra-M ercosur trade could affect internal prices and that, prima facie, the transport-cost based advantages of integration could be significant.

Table 2 offers a disaggregation of these results by sector. It shows clearly that manufactures have the smaller wedges - notably as low as $11 \%$ on machinery (electrical plus mechanical) and $16 \%$ on vehicles. As might be expected,

7. Differences in unit values in the two directions also suggest that the two flows are not identical. This implies, perhaps, that we should prefer the heterogeneous to the homogeneous goods model. 
Table 2

Transportation Wedges on US-Mercosur Trade by Sector

\begin{tabular}{|c|c|c|c|c|c|c|}
\hline & $\begin{array}{c}\text { No. of } \\
\text { Headings }\end{array}$ & $\begin{array}{c}\text { M ercosur } \\
\text { Exports } \\
\text { (\$mil.) }\end{array}$ & $\begin{array}{c}\text { M ercosur } \\
\text { Imports } \\
\text { (\$mil.) }\end{array}$ & $\begin{array}{c}\text { Transport } \\
\text { on } \\
\text { Exports }(a) \mid \\
(\%)\end{array}$ & $\begin{array}{c}\text { Transport } \\
\text { on } \\
\text { Imports(b) } \\
\text { (\%) }\end{array}$ & $\begin{array}{c}\text { Transport } \\
\text { on } \\
\text { Wedge }(c) \\
(\%)\end{array}$ \\
\hline Agriculture & 67 & 420.1 & 57.8 & 8.60 & 15.48 & 21.43 \\
\hline Cereals & 4 & 6.9 & 13.8 & 23.92 & 17.74 & 43.66 \\
\hline Other Primary Goods & 55 & 132.4 & 64.1 & 14.71 & 13.35 & 41.71 \\
\hline M ineral Fuels & 3 & 2.8 & 15.7 & 26.73 & 21.51 & 46.20 \\
\hline Salt, Sulphur, Ores & 8 & 65.3 & 3.3 & 24.08 & 18.90 & 83.73 \\
\hline M anufactures & 519 & $1,717.4$ & $1,509.4$ & 7.37 & 8.68 & 18.96 \\
\hline $\begin{array}{l}\text { Artificial Resins } \\
\text { and Plastics }\end{array}$ & 48 & 87.2 & 265.9 & 9.57 & 11.45 & 22.31 \\
\hline $\begin{array}{l}\text { Ferrous Products, } \\
\text { Iron and Steel }\end{array}$ & 86 & 250.2 & 82.9 & 8.87 & 11.33 & 21.14 \\
\hline M achinery & 32 & 280.7 & 324.9 & 5.49 & 5.33 & 11.00 \\
\hline Vehicles & 4 & 98.9 & 40.6 & 7.25 & 8.25 & 16.43 \\
\hline Textiles & 121 & 286.4 & 70.0 & 6.44 & 11.55 & 19.39 \\
\hline
\end{tabular}

a) Weighted by M ercosur's exports.

b) Weighted by M ercosur's imports.

c) Weighted by M ercosur's exports plus imports.

Calculated at 6-digit HS level, 1993, flows exceeding $\$ 30,000$ in each direction, M ercosur to US and US to M ercosur

the largest wedges are on crude primary goods followed by agriculture.

\section{Trade Shares}

The other testable necessary condition for integration to be beneficial in a homogeneous products world is that after integration the partners trade only with themselves and not with the rest of the world. ${ }^{8}$ To identify products for which this is true requires predictions of the trade effects of M erco-

8. As noted above a third condition is that the exporting partner in M ercosur exported to no-one else before integration. However, given our data, we can not test this. 
sur which we do not have. M oreover even where such predictions exist, the standard techniques for making them generally rely on differentiated goods models in which trade shares respond to relative prices but no products drop completely from the consumption set. Thus we are not well equipped to recognize cases where trade with one set of partners will wholly cease.

The best we can do is to seek to identify products for which M ercosur is currently close to self-sufficiency and thus for which it may be plausible to expect integration to eliminate third party exports. M oreover, even if products are differentiated, tariff preferences on varieties (suppliers) which account for a high share of imports are likely to have larger effects on the price of all imports in the product category than would preferences on "minor" varieties. Thus even within a differentiated goods paradigm it is useful to identify headings for which M ercosur suppliers account for a high percentage of M ercosur imports, for these are the products where the consumer benefits of integration are likely to be largest.

Table 3 divides the 6-digit HS headings into groups according to the intrabloc share of M ercosur countries' imports. It reports the share of total M ercosur imports accounted for by headings in each class, the number of headings and the average transport costs (weighted and unweighted) on M ercosur and other imports. Half of one percent of imports come from headings in which Mercosur countries already have no non-M ercosur suppliers. In these cases integration will remove a distortion and create none, and hence certainly generate welfare gains. A further $2.2 \%$ of imports come from headings in which M ercosur is heavily predominant (market share of over $95 \%$ ) and hence in which "transport-cost-based" gains are most likely, and so on. The vast bulk of imports fall in headings for which M ercosur countries take more than half their imports from non-M ercosur sources and thus for which the elimination of such trade is highly unlikely.

To get a very rough feel for the significance of these data assume that $M$ ercosur has initial tariff of $20 \%$ on the relevant goods and that the elasticity of supply for them is 2 . Then, if the abolition of the tariff on intra-bloc trade were just to eliminate third party imports-i.e. the Mercosur share were to expand to just $100 \%$ of demand but have no effect on the internal price-the initial M ercosur share would have had to be $69.4 \%{ }^{9}$ That is, third country trade would be eliminated and internal price effects would occur 
Table 3

Transport Costs on Products Classified by Mercosur Trade Shares

\begin{tabular}{|c|c|c|c|c|c|c|c|}
\hline \multirow{3}{*}{$\begin{array}{c}\text { M ercosur Share } \\
\text { of M ercosur } \\
\text { Imports }\end{array}$} & \multirow{3}{*}{$\begin{array}{l}\text { No. of } \\
\text { Headings }\end{array}$} & \multirow{3}{*}{$\begin{array}{c}\text { \%of Imports } \\
\text { in these } \\
\text { Headings }\end{array}$} & \multicolumn{4}{|c|}{ Transport Costs on Imports from: } & \multirow{3}{*}{$\begin{array}{c}\text { Assumed } \\
\text { Transport } \\
\text { Wedge }^{b} \\
\end{array}$} \\
\hline & & & Mercosur & Rest of World & Mercosur & Rest of World & \\
\hline & & & \multicolumn{2}{|c|}{ simple averages } & \multicolumn{2}{|c|}{ weighted averages $^{\mathrm{a}}$} & \\
\hline $100 \%$ & 124 & 0.5 & 13.1 & - & 13.7 & - & - \\
\hline $95-99.9 \%$ & 155 & 2.2 & 7.8 & 50.7 & 9.7 & 23.6 & 39.4 \\
\hline $80-94.9 \%$ & 230 & 3.3 & 7.3 & 19.8 & 5.5 & 14.7 & 24.6 \\
\hline $60-79.9 \%$ & 304 & 5.3 & 6.2 & 20.2 & 5.1 & 13.0 & 21.7 \\
\hline $40-59.9 \%$ & 398 & 8.5 & 6.0 & 16.5 & 3.5 & 11.6 & 19.4 \\
\hline$\leq 40 \%$ & 3,647 & 80.3 & 8.8 & 14.7 & 6.1 & 10.5 & 17.5 \\
\hline
\end{tabular}

a) Weighted by Imports from M ercosur.

b) Previous column multiplied by 1.67 --see text.

only for goods for which the initial intra-bloc share exceeded approximately $70 \%$ perhaps $8 \%$ to $9 \%$ of total M ercosur imports.

Table 3 suggests that transportation costs do influence trade shares. Where costs are highest-even intra-M ercosur costs exceed $13 \%$ the rest of the world can not compete at all. Thereafter as we move down the table, transport costs tend to fall until in the last category (M ercosur share $(40 \%)$ $M$ ercosur costs increase. This presumably partly reflects a set of commodities for which Mercosur countries have inefficient transport facilities and thus in which they can not effectively compete.

Even though only a small proportion of commodities offer good chances of transport-cost-based benefits, it is natural to ask how large those gains might be. Unfortunately we do not in general know the transportation margins payable on Mercosur exports, but following the lead of the previous section, let us assume that they are two-thirds of the margins on imports into $M$ ercosur. Applying this factor to the weighted averages of transport costs on imports from the rest of the world, the transport wedges are given

9. Removing a tariff of $20 \%$ increases the return to M ercosur suppliers from 1 to 1.2 . With an elasticity of 2 this implies a $44 \%$ increase in supply, and so to exhaust the (fixed) level of demand the initial share should be $0.6944=1 / 1.44$. It is precisely because $\mathrm{M}$ ercosur just achieves a market share of $100 \%$ that we know that the price will not change. 
Table 4

Trade and Transport Costs Disaggregated by

Mercosur Trade Shares and Sector

\begin{tabular}{|c|c|c|c|c|c|c|c|c|c|c|c|c|c|c|c|c|c|}
\hline \multirow[b]{2}{*}{ Mercosur } & \multicolumn{2}{|c|}{ Agric. } & \multicolumn{2}{|c|}{ Mineral o } & \multicolumn{2}{|c|}{$\begin{array}{c}\text { Other Prim } \\
\text { Goods }\end{array}$} & \multicolumn{2}{|c|}{ Textiles } & \multicolumn{2}{|c|}{ Footwear } & \multicolumn{2}{|c|}{$\begin{array}{l}\text { Ferrous } \\
\text { Products }\end{array}$} & \multicolumn{2}{|c|}{ M achinery } & \multicolumn{2}{|c|}{ Vehicles } & $\begin{array}{l}\text { Rest of } \\
\text { Manuf. }\end{array}$ \\
\hline & $n$ & $\$ \mathrm{~m}$ & $\mathrm{n}$ & $\$ m$ & $n$ & & $n$ & & & & & 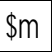 & 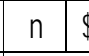 & $\$ \mathrm{~m}$ & & m & \begin{tabular}{l|l|}
$\mathrm{n}$ & $\$ \mathrm{~m}$ \\
\end{tabular} \\
\hline nare & \multicolumn{2}{|c|}{$\%$} & \multicolumn{2}{|c|}{$\%$} & \multicolumn{2}{|c|}{$\%$} & \multicolumn{2}{|c|}{$\%$} & \multicolumn{2}{|c|}{$\%$} & \multicolumn{2}{|c|}{$\%$} & \multicolumn{2}{|l|}{$\%$} & \multicolumn{2}{|c|}{$\%$} & $\%$ \\
\hline \multirow[t]{2}{*}{$100 \%$} & \begin{tabular}{l|l}
67 &
\end{tabular} & & 3 & 14 & 6 & 5 & 11 & 1 & - & & & 21 & - & & - & & \begin{tabular}{|l|l|}
27 & 14 \\
\end{tabular} \\
\hline & & & & & & & & & & & \\
\hline \multirow[t]{2}{*}{$5-99.9 \%$} & \begin{tabular}{l|l}
66 & \\
\end{tabular} & & 3 & 2 & & 45 & 21 & 17 & & & 19 & 63 & 1 & 3 & 1 & 1 & \begin{tabular}{|l|l|}
35 & 81 \\
\end{tabular} \\
\hline & \multicolumn{2}{|c|}{24.0} & \multicolumn{2}{|c|}{20.9} & \multicolumn{2}{|c|}{17.3} & \multicolumn{2}{|c|}{25.1} & & & \multicolumn{2}{|c|}{27.6} & \multicolumn{2}{|c|}{17.6} & \multicolumn{2}{|c|}{65.4} & 21.0 \\
\hline & \begin{tabular}{l|l}
54 \\
\end{tabular} & & 3 & 6 & 13 & 11 & 44 & 48 & & & 29 & 66 & 8 & 55 & & 153 & \begin{tabular}{|l|l|}
73 & 393 \\
\end{tabular} \\
\hline & 14. & & 26 & & 29. & & 12 & 2.3 & & & 14. & & 13.9 & & 9.6 & & 16.5 \\
\hline & \begin{tabular}{l|l}
49 &
\end{tabular} & & 3 & 0 & 16 & 22 & 76 & 245 & 6 & 0 & 30 & 76 & \begin{tabular}{|l|l|}
19 & 1 \\
\end{tabular} & 172 & & 309 & \begin{tabular}{|l|l|}
97 & 337 \\
\end{tabular} \\
\hline & 10. & & 14. & & 20 & & 10 & .4 & 13 & 2 & 21. & & 9.1 & & 14. & & $\frac{1}{14.7}$ \\
\hline 0 & \begin{tabular}{l|l}
48 \\
\end{tabular} & & 2 & 1 & 18 & 7 & 88 & & 2 & 8 & \begin{tabular}{|l|l|}
39 \\
\end{tabular} & 49 & \begin{tabular}{|l|l|}
32 & 1 \\
\end{tabular} & 174 & 15 & 929 & \begin{tabular}{|l|l|}
154 & 306 \\
\end{tabular} \\
\hline & 14. & & 18. & & 28. & & 12 & 2.2 & 8 & 4 & 11. & & 8.2 & & 10. & & 14.4 \\
\hline & \begin{tabular}{l|l}
343 \\
\end{tabular} & & 24 & 439 & 207 & 59 & 546 & 104 & & 20 & 31 & 91 & \begin{tabular}{|l|l|}
702 & 7 \\
\end{tabular} & 743 & \begin{tabular}{l|l}
46 \\
\end{tabular} & 149 & \begin{tabular}{|l|l|}
1577 & 863 \\
\end{tabular} \\
\hline & 15. & & 10 & 0.1 & 17 & 7.4 & & 1.9 & & 4.6 & 12 & 9 & 7.7 & 7 & 10. & & 10.8 \\
\hline
\end{tabular}

Legend: Each entry comprises three figures.

$\mathrm{n}$ - no. of headings.

$x$ - value of intra-M ercosur imports( $\$$ million)

$\tau$ - transportation costs (percentage) on imports from outside M ercosur.

in the final column of table 3. It is plain that if (as the model assumes) the current $M$ ercosur price is fixed by world prices, there is scope for substantial prices falls as a result of integration - up to nearly $40 \%$ in the $95-99.9 \%$ category and over $20 \%$ in the other plausible categories. Such price falls could generate substantial increases in consumer surpluses.

It is also interesting to consider the commodity break-down of the categories of goods in table 3 . Table 4 offers a disaggregation into industry groups with each triplet reporting the number of headings $(n)$, the value of intra-M ercosur imports $(x)$ and the transport cost on imports from outside M ercosur $\tau$. The highest trade shares are mostly found in agriculture and, indeed, for most of agriculture, trade shares are high. That implies that for 
Table 5

US-Mercosur Transport Wedges on Products

Classified by Mercosur Trade Shares

\begin{tabular}{|c|c|c|c|c|c|c|}
\hline \multirow{3}{*}{$\begin{array}{c}\text { Mercosur Share } \\
\text { of M ercosur } \\
\text { Imports }\end{array}$} & \multirow{3}{*}{$\begin{array}{l}\text { No. of } \\
\text { Headings }\end{array}$} & \multicolumn{5}{|c|}{ Transport Costs on: } \\
\hline & & $\begin{array}{l}\text { Mercosur } \\
\text { Imports } \\
\text { from US }\end{array}$ & $\begin{array}{l}\text { USImports } \\
\text { from } \\
\text { Mercosur }\end{array}$ & $\begin{array}{c}\text { M ercosur } \\
\text { Imports from } \\
\text { US }\end{array}$ & $\begin{array}{c}\text { US } \\
\text { Imports from } \\
\text { Mercosur }\end{array}$ & \multirow[t]{2}{*}{$\begin{array}{c}\text { Transport } \\
\text { Wedge }^{b}\end{array}$} \\
\hline & & \multicolumn{2}{|c|}{ simple averages } & \multicolumn{2}{|c|}{ Weighted averages a } & \\
\hline $100 \%$ & - & - & - & - & - & - \\
\hline $95-99.9 \%$ & 3 & 24.8 & 28.8 & 26.8 & 33.9 & 64.3 \\
\hline $80-94.9 \%$ & 31 & 18.6 & 15.1 & 17.0 & 7.3 & 31.7 \\
\hline $60-79.9 \%$ & 49 & 16.3 & 10.9 & 15.5 & 7.2 & 22.6 \\
\hline $40-59.9 \%$ & 87 & 16.7 & 11.3 & 15.7 & 7.4 & 19.3 \\
\hline$\leq 40 \%$ & 467 & 12.0 & 10.1 & 8.5 & 8.3 & 18.5 \\
\hline
\end{tabular}

a) Weighted by Mercosur's and US imports respectively.

b) Weighted by sum of M ercosur's and US imports.

Trade values less than US\$30,000 are excluded.

agriculture M ercosur could generate significant transport-cost-based benefits. The next most likely groups are ferrous products and textiles relatively and the rest of manufacturing absolutely.

Table 5 extends this analysis to calculate the transport wedges more precisely on US-M ercosur trade. The classification of trade headings by M ercosur trade shares is the same as in table $3,{ }^{10}$ but now we focus on the sub-set for which we can identify M ercosur-US trade in both directions exceeding $\$ 30,000$-i.e. the set of headings analyzed in table 2 . The sample is much smaller than previously--only 641 headings in al -and it suggests somewhat larger wedges than previously, especially in the relevant "high-share" categories.

The conclusion of this section is that while transport wedges in international trade are significant and appear to give plenty of scope for benefits from regional integration, comparative advantage is less kind. Rather few

10. The trade headings in each class in table 5 are a sub-set of those in the corresponding class in table 3. 
goods fall into the classes for which such gains seem plausible. Essentially we are seeking goods for which member exporters have no pre-integration third-country partners and member importers have no post-integration third-country partners. We can not apply the former criterion at our level of aggregation, but less than $10 \%$ of current $\mathrm{M}$ ercosur imports fall into headings for which the latter is plausible. All told, therefore, we should not expect major transport-cost-related gains to integration through this causal channel.

\section{The Scope for Transport Efficiency Gains}

Identifying the scope and the means for improvements in the efficiency of international transportation is a technical and information-intensive activity. We do not pretend to be able to undertake a full investigation, but it does seem sensible to develop our data sources a little in this direction. We consider the transportation component of costs for M ercosur's and the United States' imports from a series of distant suppliers, roughly equidistant from M ercosur and the United States - Germany, Japan, India and Thailand. By choosing distant suppliers we hope to maximize the differences in costs on the two routes and reduce the effects of any idiosyncratic features of the exporter's circumstances. We do this only for Argentina, Brazil and Chile because the number of trade headings for which both U ruguay (Paraguay) and the U nited States import material amounts for the same source is very limited. We also restrict ourselves to headings in which both the United States and M ercosur report trade by weight, so that we can examine cost both per unit of value and per unit of weight.

Table 6 reports four statistics for each exporter-importer pair: the number of HS 6-digit trade headings for which both the United States and the $M$ ercosur country imported over $\$ 30,000$ from the exporter; the percentage of these for which the difference in percentage transport costs (U nited States minus M ercosur) is positive (i.e., US costs exceed those of the M ercosur country); the unweighted difference and the weighted difference (weighted by the M ercosur country's imports). Particularly for the larger exporters Germany and Japan there are good sized samples and firm evidence that M ercosur's costs exceed the United States. This is true of over 
Table 6

D ifferences between Transport Costs on Export to the United States and to Main Latin American Countries ${ }^{a}$

\begin{tabular}{|l|c|r|r|}
\hline \multicolumn{4}{|c|}{ M arket } \\
\hline Exporter & Argentina & B razil & Chile \\
\hline \multicolumn{4}{|c|}{ no. of trade headings } \\
\hline Germany & 722 & 785 & 600 \\
Japan & 236 & 412 & 200 \\
India & 86 & 21 & 21 \\
Thailand & 25 & 6 & 33 \\
\hline \multicolumn{4}{|c|}{ \%of positive differences } \\
\hline Germany & 19 & 18 & 17 \\
Japan & 11 & 16 & 13 \\
India & 10 & 14 & 24 \\
Thailand & 8 & 0 & 21 \\
\hline \multicolumn{4}{|c|}{ mean difference in percent (unweighted) } \\
\hline Germany & -3.0 & -4.0 & -3.77 \\
Japan & -5.7 & -8.2 & -6.5 \\
India & -7.8 & -5.7 & -4.8 \\
Thailand & -8.4 & -6.1 & -4.8 \\
\hline \multicolumn{4}{|c|}{ mean difference in percent (weighted) } \\
\hline Germany & -2.0 & -1.8 & -4.1 \\
Japan & -4.1 & -5.1 & -7.4 \\
India & -7.8 & -3.3 & -5.2 \\
Thailand & -4.3 & -7.3 & -4.1 \\
\hline
\end{tabular}

a) Commodities for which exports to both US and Latin American countries exceed $\$ 30,000$ and for which US reports trade quantities by weight.

$80 \%$ headings and the average difference is $2-4 \%$ for Germany and $4-8 \%$ for Japan. For geographical reasons one might expect the differences to be larger for Germany-Chile, and J apan-Argentina-Brazil. There is a small amount of evidence for higher Germany-Chile differentials in the weighted averages, but not in the unweighted averages or proportion-positive counts. M oreover, Chile's disadvantage seems to be larger for imports from Japan. The results in table 6 are not strictly comparable across columns because the 
headings included vary by importer - the requirement was that the United States and, say, Brazil both import the good from the exporters. If we recalculate it, however, using only headings imported (over $\$ 30,000$ ) by the United States and all three M ercosur importers, the story remains the same.

Turning to the developing country exporters the samples are much smaller, but the story is much the same-slightly greater differentials for Argentina and Brazil and slightly smaller for Chile, as geography dictates. In these cases, however, the number of headings relevant to all three importers is zero for India and one for Thailand, so strict cross-M ercosur comparisons are not possible.

Since the United States may import higher quality (dearer) goods than $M$ ercosur it may be that its lower percentage transport cost reflects equal absolute costs deflated by a higher value in the denominator. Recalculating table 6 on the basis of transport costs per kilogram suggests that this is not the case. The proportion of positive differences increases for Argentina to around one quarter, but all the averages are still firmly negative.

This section has identified that, on average, the major M ercosur countries pay more for transporting their imports than does the United States, but it does not say why. It may be due to largely unavoidable factors such as smaller consignment size, smaller overall volumes, or different seasonality. It may, on the other hand, be due to the age of equipment, competition in the transportation sector, or port efficiency. ${ }^{11}$ The fact that Chile shows no advantage over Argentina and Brazil, however, casts some doubt on the latter factors, however, for Chile undertook fairly major reforms in the 1980s- - see B ennathan [1989]. M oreover, since 1993 several reforms and modernizations have been made, so even if we have identified problems in our exercise, they may be on their way to being resolved.

\section{Conclusion}

This paper has explored what benefits might occur to the introduction of free trade between the $M$ ercosur countries and Chile as a result of their

11. Inefficient ports can raise reported shipping costs because they increase the turnaround times on ships and planes. 
geographical proximity. It found that transportation margins on intra-M ercosur and M ercosur-Chile trade are lower than those on trade with the rest of the world by about 6 percentage points. This is a significant margin and it was presumably reflected in the countries' trade patterns even before regional arrangements reduced the policy-based barriers to mutual trade. When it is interacted with such regional arrangements, however, a margin of 6 percentage points is rather small, and offers little justification in and of itself for pursuing regional preferences. That is, the benefits or costs of regional integration are not very different if the transport cost differential is $6 \%$ from if it is zero. Thus M ercosur plus Chile is not sufficiently much of a natural trading bloc (in terms of transportation costs) to warrant the introduction of preferences in the absence of other resulting benefits.

The conclusion of the previous paragraph reflects a comparison between observed transportation margins and M ercosur imports- - -derived originally for this paper - with theoretical values derived by Frankel, Stein and Wei [1995]. To the extent that the latter's model is not applicable to the real world - a fairly significant extent - it is, of course, tentative.

A second approach to assessing the effects of transportation costs on the benefits of regional integration focuses just on the costs of trading with the rest of the world. The sum of these costs on exports and on imports defines a range of prices within which a good becomes non-traded for the M ercosur region -in the sense of conducting no trade with the non-M ercosur world. Within these wedges regional integration can affect local prices and thus have significant effects on economic welfare. These wedges appear to be large-over $40 \%$ in some cases and frequently over $20 \%$ However, the set of goods for which it is plausible that trade with the rest of the world will cease following the introduction of Mercosur preferences is small --certainly no more than $10 \%$ of total M ercosur imports. Overall, therefore, it seems that $M$ ercosur is not a sufficiently "natural" bloc in this second sense either to reap big rewards from regional ar rangements.

Finally, we explored the relative sizes of transportation costs on imports into the main $M$ ercosur countries and into the United States. The evidence suggests that Mercosur pays two to four percentage points more. Future research and policy analysis might usefully explore why. 


\section{References}

Bhagwati, J.N. and A. Panagariya [1996], "Preferential Trading Areas and M ultilateralism: Strangers, Friends of Foes?" in Bhagwati, J.N. and Panagariya A. (eds.) Free Trade Areas or Free Trade? The E conomics of Preferential Trading Agreements, AEI Press, Washington, D.C

Bennathan, E. [1989], "Deregulation of Shipping: What is to be Learned from Chile," World Bank Discussion Paper N o. 67, The World Bank, Washington, D.C.

Frankel, J.A., E. Stein and S. J.Wei [1995], "Trading Blocs and the Americas: The Natural, the Unnatural, and the Super-N atural," J ournal of Devel opment E conomics 47; 61-95.

Hufbauer, G.C. and Schott, J.J. [1994], Western Hemisphere Economic Inte gration, Institute for Inter national Economics, Washington D.C.

Krugman, P. [1991], "The M ove Towards F ree Trade Zones," in Policy Implications of Trade and Currency Zones, A Symposium Sponsored by the Federal Reserve Bank of Kansas City, Jackson Hole, Wyoming; 7- 42.

Krugman, P. [1991], "Is Bilateralism Bad?," in Helpman, E. and Razin, A.(eds) International Trade and Trade Policy, Cambridge M A, M IT Press.

Nitsche, V. [1996], "D o Three Trade Blocs M inimize World Welfare?" Review of International Economics 4(3); 355-363

Schiff, M aurice [1996], "Small is Beautiful: Preferential Trade Agreements and the Impact of County Size, M arket Share, and Smuggling," Jour nal of E conomic Integration 12; 359-387

W inters, L.A. [1996], "Regionalism versus M ultilateralism," Discussion Paper Series N o. 1525, Centre for Economic Policy Research, London.

Wonnacott, P. and Wonnacott, R. [1981], "Is Unilateral Tariff Reduction Preferable to a Customs Union? The Curious Case of the M issing Foreign Tariffs," American E conomic Review 71(4); 704-14.

Wonnacott, P. and Wonnacott, R. [1992], "The Customs Union Issue Reopened," Manchester School of E conomics and Social Studies 60(2); 119-35. 